\title{
Analysis of the Retrogradation Processes in Potato Starches Blended with Non-Starchy Polysaccharide Hydrocolloids by LF NMR
}

\author{
Hanna Maria Baranowska ${ }^{1}$ (D) Marek Sikora ${ }^{2} \cdot$ Magdalena Krystyjan $^{2} \cdot$ Anna Dobosz $^{2} \cdot$ Piotr Tomasik $^{3}$. \\ Katarzyna Walkowiak ${ }^{1,4} \cdot$ Łukasz Masewicz $^{1} \cdot$ Barbara Borczak $^{5}$
}

Received: 10 December 2018 / Accepted: 24 July 2019 /Published online: 9 August 2019

(C) The Author(s) 2019

\begin{abstract}
Molecular dynamics for pastes of two normal and one waxy potato starches and their binary mixtures with either arabic, guar or xanthan gum was determined. Spin-lattice and spin-spin relaxation times were measured by 1 H NMR pulse spectrometer. Then, for water molecules the mean correlation time rotational mobility. Was calculated and analyzed. The measurements were taken after $2 \mathrm{~h}$, and then after 1, 10,30 and 90 days of storing at $5{ }^{\circ} \mathrm{C}$. It was found that the susceptibility of pastes of potato starch to retrogradation was controlled, first of all, by the content of amylose. Amylose favored retrogradation. On the initial period of storing the length of the amylose chains played an essential role promoting retrogradation. Non-starchy polysaccharide hydrocolloids applied for blending potato starches influenced molecular properties of water in the pastes, particularly on long-term retrogradation. Generally, these components retarded that process.
\end{abstract}

Keywords Arabic gum $\cdot$ Guar gum $\cdot$ Normal potato starch $\cdot$ Relaxation times $\cdot$ Waxy potato starch $\cdot$ Xanthan gum

\section{Introduction}

Starch gels being originally amorphous gradually crystallize. That process is known as retrogradation [1-6]. Retrogradation rate and degree is associated with the botanical origin of starch [7,8] that is, among others with the fine structure of amylose and amylopectin [7, 9-11], the amylose/amylopectin ratio [10, 12-14].

Retrogradation influences the texture, stability, quality, digestibility and functionality of starch pastes and starch

Hanna Maria Baranowska

hanna.baranowska@up.poznan.pl

1 Department of Physics and Biophysics, University of Life Sciences, Poznan, Wojska Polskiego Street 38/42, 60-637 Poznan, Poland

2 Faculty of Food Technology, Department of Carbohydrates Technology, University of Agriculture in Krakow, Balicka Street 122, 30-149 Krakow, Poland

3 Nantes Nantes Nanotechnological Systems, Dolne Młyny Street 21, 50-700 Bolesławiec, Poland

4 Faculty of Technical Physics, Poznan University of Technology, Piotrowo Street 3, 60-965 Poznan, Poland

5 Faculty of Food Technology, Department of Human Nutrition, University of Agriculture in Krakow, Balicka Street 122, 30-149 Krakow, Poland containing products [15]. Usually its results are considered negative [16] but sometimes, for instance, in a low-energy food production retrogradation is considered beneficial as it delivers resistant starch (RS) [17-19].

Retrogradation proceeds in two short- and long-term steps, respectively. In the short-term step amylose crystallizes and that step of retrogradation begins already within first few hours since starch gelation and it can last up to two days. The long-term retrogradation is associated with recrystallization of the outer branches of amylopectin. Compared to retrogradation of amylose the latter is considerably slower [20,21]. The changes of retrogradations were observed in chemically modified starches [17, 22]. Recently, a number of papers was published on blends of starches with various non-starchy polysaccharides, particularly with natural and synthetic gums. They attracted attention as novel materials for food technology, for instance, texturizing agents, packaging foils and other biodegradable materials [20, 23-27]. Their applicability depends, among others, on their stability against retrogradation. It was shown that retrogradation rate and degree are sensitive to various hydrocolloids [28-30].

Progress of starch retrogradation can be monitored involving several techniques.

Among them also NMR spectrometry appeared useful. ${ }^{13} \mathrm{C}$ CPMASS NMR was used when the retrogradation in the solid state was investigated [31]. Considerable attention was paid to 
the observation of the fate of the water molecules on retrogradation. In such case the spin-lattice and spin-spin relaxation times were observed based on ${ }^{17} \mathrm{O}$ NMR [32] and ${ }^{1} \mathrm{H}$ NMR [33-35] studies. In the latter case the studies involved a rule that in the systems with a considerable mobility of molecules are characterized with longer spin-spin relaxation times. A decrease in the mobility of such molecules is reflected by shortening of those relaxation times. As the viscosity of those systems increases, the rate of the spin-spin relaxation increases, that is, the spin-spin relaxation time decreases. It is generally accepted that spin-lattice, $\mathrm{T}_{1}$, and spin-spin, $\mathrm{T}_{2}$, relaxation times qualitatively and quantitatively describe binding water in the system.( [36]. Molecular dynamics can be determined based on average correlation time, $\tau_{c}$, which is a microscopic parameter [37]. Relaxation times in biological systems including pastes and gels provide an information on a mode of binding water to macromolecular polymeric systems and reorientation of the water molecules evoked by big polymeric molecules.

The aim of study was analyze the short and long term of retrogradation process in starch and starch-hydrocolloids mixtures from molecular point of view.

\section{Materials and Methods}

\section{Materials}

Normal potato starches NPS1 and NPS2 and waxy potato starch WPS containing estimated according to Morrison and Laignelet [38] 29.93\%, 26.72\% and 9.27\% amylose, respectively were studied. NPS1 was isolated in Department of Carbohydrate Technology of the University of Agriculture in Cracow from the planted in 2013 Tajfun variety purchased from Stacja Doświadczalna Oceny Odmian (Węgrzce, Poland). NPS2 was purchased from Przedsiębiorstwo Przemysłu Ziemniaczanego Bronisław Sp. z o.o. (Strzelno, Polska). WPS, commercial Eliane 100, was manufactured by AVEBE FOOD (Veendam, the Netherlands). Non-starchy polysaccharide hydrocolloids: Arabic gum (AG), xanthan gum $(\mathrm{XG})$ and guar gum $(\mathrm{GG})$ were purchased from Sigma Aldrich (St. Louis, USA).

\section{Sample Preparation}

The study were perform on the $5 \mathrm{w} \%$ starch paste samples or samples composed of $4.8 \mathrm{w} \%$ starch $0.2 \mathrm{w} \%$ hydrocolloid added. The sols of starch and their blends with particular hydrocolloids were heated on a gentle stirring for $30 \mathrm{~min}$. at $90{ }^{\circ} \mathrm{C}$. Resulting hot pastes $\left(0.2 \mathrm{~cm}^{3}\right)$ were passed into measurement viols, closed with parafilm and allowed to stand for cooling to room temperature. So thermally equilibrated samples in the measurement viols were cooled to $5{ }^{\circ} \mathrm{C}$ in an ice shrank.

\section{Relaxation Time Measurements}

Relaxation times were taken after $2 \mathrm{~h}$, and then after 1, 10, 30 and 90 days of storing at $5{ }^{\circ} \mathrm{C}$. The measurements of spinlattice $\left(\mathrm{T}_{1}\right)$ and spin-spin $\left(\mathrm{T}_{2}\right)$ relaxation times were conducted by the use of PS15T pulse ${ }^{1} \mathrm{H}$ NMR spectrometer (ELLAB, Poznań, Poland), at $15 \mathrm{MHz}$, equipped with integral temperature control system. Prior to the experiments, samples placed in the spectrometer were allowed to reach $20^{\circ} \mathrm{C}$.

The inversion-recovery $(\pi-t-\pi / 2)$ impulse sequence [36] was applied for measurements of the $T_{1}$ relaxation times. Distances ( $t$ ) between RF pulses were changed within the range from 100 to $1000 \mathrm{~ms}$ and the repetition time was from 20 s. Each time, 32 FID signals and 119 points from each FID signal were collected.

Calculations of the spin-lattice relaxation time values were performed with the assistance of the CracSpin software [39]. That software provided calculating relaxation parameters from experimental data using "spin grouping" approach. Marquardt's method of minimization has been applied for fitting multiexponential decays. The accuracy of the relaxation parameters was estimated and the standard deviations were given. Time changes of the current value of the FID signal amplitude in the employed frequency of impulses were described by the following formula:

$M_{z}(t)=M_{0}\left(1-2 e^{\frac{-t}{T_{1}}}\right)$

where: $M_{z}(t)$ - is the actual magnetisation value, $M_{0}$ - is the equilibrium magnetisation value, $\mathrm{t}$ - is the distance between impulses and $T_{1}$ - is the spin-lattice relaxation time.

Measurements of the $T_{2}$ spin-spin relaxation times were taken using the pulse train of the Carr-Purcell-Meiboom-Gill spin echoes $\left(\pi / 2-\tau / 2-(\pi)_{n}\right)$ [36]. The distance (t) between $\pi$ impulses amounted to $2 \mathrm{~ms}$. The repetition time was $15 \mathrm{~s}$. The number of spin echoes (n) amounted to 100 . Tree accumulation signals were employed.

To calculate the spin-spin relaxation time values, the authors applied the adjustment of values of the echo amplitudes to the Eq. (2):

$M_{x, y}(t)=M_{0} e^{\frac{-t}{T_{2}}}$

where: $M_{x, y}(t)$ - is the echo amplitude; $M_{o}$ - is the equilibrium amplitude; $\mathrm{t}-$ is the distance between $\pi$; impulses; $\mathrm{T}_{2}$ is the spin-spin relaxation time.

The calculations were performed with the dedicated software involving non-linear least-square algorithm. The accuracy of the relaxation parameters has been estimated with the standard deviations. 


\section{Results and Discussion}

Table 1 collects the spin-lattice, $T_{1}$, and spin-spin, $T_{2}$, relaxation times for $5 \%(\mathrm{~g} / \mathrm{g})$ starch pastes without and with admixture of non-starchy polysaccharide hydrocolloids measured after $2 \mathrm{~h}$, and 1, 10, 30 and 90 days storing.

For all NPS pastes regardless the period of their storage in an ice shrank up to 90 days only one spin-lattice $\left(T_{1}\right)$ and one spin-spin $\left(\mathrm{T}_{2}\right)$ relaxation time could be observed. It was characteristic for biopolymers pastes $[35,40]$. It suggested that in spite of progressing retrogradation of starches there was a fast chemical exchange, that is, the within the time necessary for the energy transfer from spin into environment as well as into to another spin, molecules of water could migrate from one fraction of water into another.

Already after the $2 \mathrm{~h}$ storage some differences in spinlattice $\left(T_{1}\right)$ and spin-spin $\left(T_{2}\right)$ relaxation times for particular NPSs could be noted (Table 1) suggesting some differences in the formation of the paste networks on cooling. NPS1 paste after $2 \mathrm{~h}$ showed higher $\mathrm{T}_{1}$ and $\mathrm{T}_{2}$, than these for NPS2. That observation rationalized an assumption that NPS1 paste after $2 \mathrm{~h}$ storing in spite of higher amylose content were less rigid than pastes of NPS2 and WPS and, in consequence, water molecules in the NPS1 paste could more freely rotate [41]. On storing the NPS2 and WPS pastes for $2 \mathrm{~h}$ the relaxation times, particularly $\mathrm{T}_{1}$ only slightly changed. The NPS2 paste showed the lowest $T_{1}$ whereas the WPS paste had the lowest $\mathrm{T}_{2}$. Thus, on could assume that $\mathrm{T}_{2}$ decreased with amylose content in starch (Table 1). Relationships between $\mathrm{T}_{1}$ for particular pastes under study were close to the values of relative degree of crystallinity calculated involving diffractometry. The calculations for results collected for the pastes after $2 \mathrm{~h}$ storage gave $\mathrm{DoC}_{\mathrm{w}}$ declining from NPS1 to NPS2 [42].

Observed values for the relaxation times were typical for those collected when low frequency electromagnetic waves were applied [41, 43, 44]. These values varied with the time of storage of the pastes. In the first day, $\mathrm{T}_{1}$ for the NPS1 pastes declined suggesting reducing mobility of the water molecules due to a reconstruction of the paste network whereas at the same storage period $T_{1}$ for the NPS2 and WPS increased. The NPS1 contain the most amylose. This biopolymer bound water molecules in this short time during storage. Moreover, both $\mathrm{T}_{1}$ and $\mathrm{T}_{2}$ taken at that storage period for WPS were considerably lower than these for NPS2 pointing to a different network structure of both those pastes. This explain main role of amylose in network forming. These changes in $\mathrm{T}_{1}$, dependent on the starch variety, followed changes in $\mathrm{DoC}_{\mathrm{w}}$ for those starches [42].

Relaxation times significantly changed on extension of the storage period to 90 days. The NPS1 pastes showed the longest relaxation times compared to the pasts of the other starches. It suggested that the NPS1 paste formed structures richer in the free water fraction, that is, structures containing particular water molecules surrounded with a coats of other water molecules [45]. Small declining $\mathrm{T}_{1}$ was not accompanied with any changes of $T_{2}$ what could mean that on prolonged storage in the gel formed within first 1 day, dynamics of the water molecules did not changed anymore.
Table 1 Spin-lattice, $\mathrm{T}_{1}$, and spin-spin, $T_{2}$, relaxation times for $5 \%(\mathrm{~g} / \mathrm{g})$ starch pastes without and with admixture of nonstarchy polysaccharide hydrocolloids after $2 \mathrm{~h}$, and 1, 10, 30 and 90 days storing at $5^{\circ} \mathrm{C}$

\begin{tabular}{lllllllll}
\hline Storage time & $\mathrm{T}_{1}[\mathrm{~ms}]$ & $\mathrm{T}_{2}[\mathrm{~ms}]$ & $\mathrm{T}_{1}[\mathrm{~ms}]$ & $\mathrm{T}_{2}[\mathrm{~ms}]$ & $\mathrm{T}_{1}[\mathrm{~ms}]$ & $\mathrm{T}_{2}[\mathrm{~ms}]$ & $\mathrm{T}_{1}[\mathrm{~ms}]$ & $\mathrm{T}_{2}[\mathrm{~ms}]$ \\
\hline & $\mathrm{NPS} 1$ & & $\mathrm{NPS} 1+\mathrm{XG}$ & $\mathrm{NPS} 1+\mathrm{GG}$ & $\mathrm{NPS} 1+\mathrm{AG}$ \\
$2 \mathrm{~h}$ & $1691 \pm 4$ & $1070 \pm 8$ & $1574 \pm 3$ & $871 \pm 9$ & $1692 \pm 3$ & $808 \pm 7$ & $1725 \pm 4$ & $946 \pm 1$ \\
$1 \mathrm{~d}$ & $1567 \pm 4$ & $1142 \pm 6$ & $1597 \pm 4$ & $877 \pm 5$ & $1533 \pm 4$ & $624 \pm 5$ & $1621 \pm 4$ & $727 \pm 9$ \\
$10 \mathrm{~d}$ & $1542 \pm 4$ & $1023 \pm 8$ & $1616 \pm 8$ & $865 \pm 3$ & $1523 \pm 4$ & $678 \pm 9$ & $1640 \pm 4$ & $602 \pm 9$ \\
$30 \mathrm{~d}$ & $1573 \pm 3$ & $988 \pm 9$ & $1577 \pm 3$ & $842 \pm 6$ & $1493 \pm 3$ & $955 \pm 9$ & $1595 \pm 4$ & $977 \pm 1$ \\
$90 \mathrm{~d}$ & $1336 \pm 3$ & $893 \pm 5$ & $1582 \pm 4$ & $653 \pm 9$ & $1297 \pm 4$ & $959 \pm 3$ & $1434 \pm 4$ & $823 \pm 2$ \\
& $\mathrm{NPS} 2$ & & NPS2+XG & NPS $2+\mathrm{GG}$ & $\mathrm{NPS} 2+\mathrm{AG}$ \\
$2 \mathrm{~h}$ & $1426 \pm 3$ & $872 \pm 3$ & $1602 \pm 4$ & $865 \pm 2$ & $1515 \pm 4$ & $914 \pm 2$ & $1433 \pm 4$ & $820 \pm 11$ \\
$1 \mathrm{~d}$ & $1500 \pm 5$ & $726 \pm 5$ & $1477 \pm 3$ & $743 \pm 8$ & $1418 \pm 8$ & $724 \pm 10$ & $1453 \pm 5$ & $736 \pm 5$ \\
$10 \mathrm{~d}$ & $1460 \pm 4$ & $545 \pm 2$ & $1464 \pm 4$ & $674 \pm 5$ & $1416 \pm 3$ & $657 \pm 9$ & $1419 \pm 4$ & $566 \pm 6$ \\
$30 \mathrm{~d}$ & $1240 \pm 8$ & $575 \pm 6$ & $1414 \pm 4$ & $646 \pm 9$ & $1336 \pm 4$ & $547 \pm 6$ & $1297 \pm 3$ & $555 \pm 9$ \\
$90 \mathrm{~d}$ & $910 \pm 6$ & $98 \pm 7$ & $1374 \pm 3$ & $576 \pm 4$ & $1277 \pm 4$ & $586 \pm 1$ & $1383 \pm 4$ & $503 \pm 8$ \\
& $\mathrm{WPS}$ & & WPS $+\mathrm{XG}$ & & WPS $+\mathrm{GG}$ & & WPS $+\mathrm{AG}$ & \\
$2 \mathrm{~h}$ & $1466 \pm 8$ & $726 \pm 1$ & $1534 \pm 4$ & $790 \pm 12$ & $1585 \pm 6$ & $808 \pm 10$ & $1623 \pm 4$ & $929 \pm 10$ \\
$1 \mathrm{~d}$ & $1471 \pm 4$ & $700 \pm 4$ & $1544 \pm 4$ & $797 \pm 18$ & $1528 \pm 4$ & $802 \pm 16$ & $1517 \pm 4$ & $900 \pm 5$ \\
$10 \mathrm{~d}$ & $1302 \pm 3$ & $680 \pm 4$ & $1514 \pm 3$ & $750 \pm 7$ & $1432 \pm 4$ & $708 \pm 6$ & $1453 \pm 3$ & $827 \pm 7$ \\
$30 \mathrm{~d}$ & $1315 \pm 2$ & $660 \pm 4$ & $1519 \pm 3$ & $689 \pm 4$ & $1437 \pm 3$ & $658 \pm 5$ & $1450 \pm 3$ & $799 \pm 8$ \\
$90 \mathrm{~d}$ & $1285 \pm 4$ & $603 \pm 5$ & $1416 \pm 3$ & $672 \pm 3$ & $1372 \pm 4$ & $600 \pm 7$ & $1351 \pm 4$ & $783 \pm 8$ \\
\hline
\end{tabular}

The mean values $\pm \mathrm{SD}$ 
This was not a case for the NPS2 pastes. On their storage up to 90 days $T_{1}$ and $T_{2}$ declined perhaps due to a loss free water as the result of limiting mobility being a consequence of binding water in the paste network. In the WPS pastes relaxation times changed within the 30 days storage and then they stabilized delivering an evidence for the stabilization of the paste network structure. Comparison of the values of the relaxation times after 90 days storage led to a conclusion that in every paste water was evacuated from the polymer network nodes forming the fraction of free water. Additionally, large differences in the relaxation times for particular pastes pointed to differences in the modes of interactions between water and starch and between starch chains. Thus, on could state that long-term changes in particular pastes differed from one another. Variation of the relaxation times provided quantitative analysis of changes resulting from binding water and dynamics of the water molecules. The relaxation times collected employing low-field NMR allow an insight into rotational modes of the water molecules in the system.

In binary pastes of NPS1 with non-starchy hydrocolloids the mobility of the water molecules was substantially limited. Simultaneously, quantitative changes in the free and bound water molecules could be observed solely in the NPS1 - XG pastes (Fig. 2). In this case the monotonical increase of mean correlation times was observed. It suggested that considerable number of water molecules participated in the network formation. Shorter relaxation times compared to those in the pastes free of the non-starchy hydrocolloids likely resulted from the intervention of hydrogen bonds in building nodes of the paste networks.

Binary NPS2 - non-starchy hydrocolloid systems showed higher $T_{1}$ values than these for pure NPS2 pastes. $T_{2}$ for the binary paste of that starch with GG also increased whereas it remained unchanged in case of the corresponding gels with $\mathrm{XG}$ and $\mathrm{AG}$. That finding might be an evidence for a weak starch - GG interactions as well as for a higher content of free water in that binary system as compared to the NPS2 paste. In the binary pastes of that starch with XG and AG dynamic properties of water in the paste did not change.

In WPS binary pastes both relaxation times measured after $2 \mathrm{~h}$ storage increased as compared to the pastes free of hydrocolloids. It delivered an argument that WPS did not interact with those hydrocolloids (Table 1).

Changes of $T_{1}$ and $T_{2}$ on storage of NPS1 - XG binary pastes were relatively small. It could be rationalized in terms of a high stability of the network and its resistance to retrogradation. In contrast to the behavior of $\mathrm{T}_{1}$ and $\mathrm{T}_{2}$ in these binary pastes, these parameters for the pastes with both remained hydrocolloids considerably changed on prolonged storage. $\mathrm{T}_{1}$ for the binary pastes of NPS1 with GG and AG decreased pointing to decreasing amount of free water in the pastes on prolonged time of their storage. The NPS1 binary paste with AG held more such water than the NPS1 - GG paste. Changes of $T_{2}$ reflecting changes of molecular dynamics showed that after
1 day storage of binary pastes of NPS1 with GG and AG was significantly reduced. After 30 days storage $T_{2}$ rose as a consequence of an increase in the mobility of the water molecules, that is, of increased syneresis. After the 90 days storage in the NPS1 binary paste with GG dynamics of the water molecules remained constant whereas in the relevant binary paste with AG the limitation of the water molecules mobility progressed. Thus, one could state that XG most efficiently limited retrogradation of starch and $A G$ was least efficient in that respect. $T_{1}$ and $T_{2}$ of binary pastes of NPS2 with non-starch hydrocolloids declined on the storage showing that the water was successively arrested inside the paste network. Significant shortening of both relaxation times was observed just after 30 days what meant that in that period retrogradation progressed efficiently. These changes were least dynamic in the binary paste with XG manifesting that this paste was most stable on the storage, that is, it was most resistant to retrogradation. In the paste of NPS2 with AG $T_{1}$ rose up to 90th day as a result of the change of the proportion of free and bound water. On storage, relevant $\mathrm{T}_{1}$ and $\mathrm{T}_{2}$ monotonously declined with the storage time. Like in binary NPS2 pastes, these parameters for the WPS - XG binary pastes changed to a least extent. Likely that behavior was associated with binding water by $\mathrm{XG}$ rather than retarding retrogradation.

The rate of the relaxation processes in biological systems is controlled to a great extent by molecular mobility. Depending on the environment of water, in the biopolymer network which is formed its binding may involve either hydrogen or ionic bonds. Such binding allows free rotation of the water molecules around such bonds. It is also known that in such structures some water molecules are arrested in the nodes of the polymeric network. It significantly limits their dynamics.

In such biological systems as biopolymeric pastes including starch pastes of the concentration up to approximately $15 \%$, usually one component of both relaxation times can be observed. It means that between molecules of water bound to macromolecule and free water a fast chemical exchange takes place. In such cases a mean time of the correlation can be determined. That parameter allows determination of the possibility of free rotation of the water molecules and its limited dynamics in the polymeric networks [46]. Mean correlation times, $\tau_{c}$, can be derived from the relaxation times, $T_{1}$ and $T_{2}$ involving the system of the BPP equations (Eqs. 3 and 4) [47, 48]. This BPP relaxation rates $1 / T_{1}$ and $1 / T_{2}$ concern spin pair of protons.

$$
\begin{aligned}
& \frac{1}{T_{1}}=\frac{3}{10} \frac{\mu_{0}^{2}}{16 \pi^{2}} \frac{\gamma^{4} \hbar^{2}}{r_{0}^{6}}\left[\frac{\tau_{c}}{1+\left(\varpi \tau_{c}\right)^{2}}+\frac{4 \tau_{c}}{1+\left(2 \varpi \tau_{c}\right)^{2}}\right] \\
& \frac{1}{T_{2}}=\frac{3}{20} \frac{\mu_{0}^{2}}{16 \pi^{2}} \frac{\gamma^{4} \hbar^{2}}{r_{0}^{6}}\left[3 \tau_{c}+\frac{5 \tau_{c}}{1+\left(\varpi \tau_{c}\right)^{2}}+\frac{2 \tau_{c}}{1+\left(2 \varpi \tau_{c}\right)^{2}}\right]
\end{aligned}
$$

where: $\mu_{0}$ is the magnetic permittivity in vacuum $\left[\mathrm{m} \mathrm{kg} \mathrm{s}^{-2}\right.$ $\left.\mathrm{A}^{-2}\right], \gamma$ is a hygrometric coefficient $\left[\mathrm{s}^{-1} \mathrm{~T}^{-1}\right], \hbar$ is the Planck 
Fig. 1 Changes of the mean correlation time in $5 \%(\mathrm{~m} / \mathrm{m})$ starch pastes after $2 \mathrm{~h}$ ( 0.12 day) and after 1, 10, 30 and 90 days storage at $5^{\circ} \mathrm{C}$

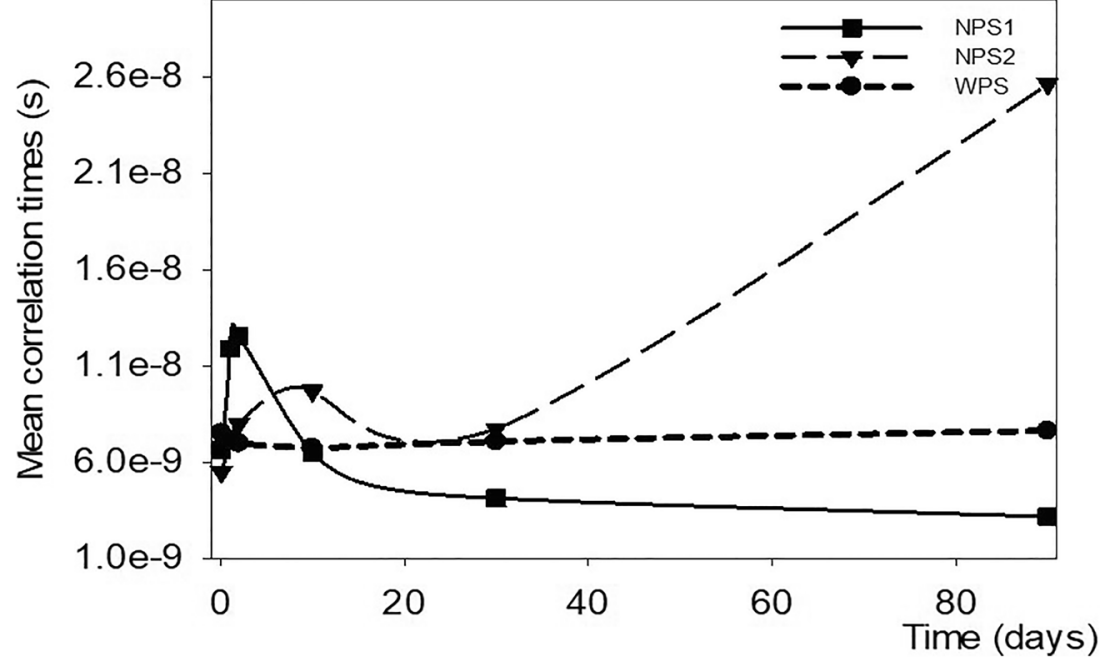

constant divided by $2 \pi\left[\mathrm{m}^{2} \mathrm{~kg} \mathrm{~s}^{-1}\right]$, and $\mathrm{r}_{0}$ is a distance between water protons $[\mathrm{m}]$.

The time-dependent changes of mean correlation times in analyzed starch pastes are presented in Fig. 1. Mean correlation times for stored samples showed that studied pastes distinguished from one another in molecular dynamics. NPS1 pastes were characterized with the shortest relaxation times indicating that in these pastes the water molecules had the best opportunity for rotation and that these pastes contained the most free water. It could be associated with the highest amylose content in that starch. It facilitated retrogradation of those pastes. Moreover, in the stored pastes the mean correlation times declined pointing to a successive release of the water molecules from the network. NPS2 formed polymeric structures for whose the mean correlation times significantly increased from the 10th day storage. Such behavior could result from obscuring molecular movements by a formation of stable solid state structures. In the WPS pastes dynamics of water molecules remained stable in time pointing to the stability of the relevant molecular systems.

Figures 2, 3 and 4 present variation of the mean correlation times in pastes of starches and their binary systems with nonstarchy hydrocolloids.

Insight in the mean correlation times for binary NPS1 - hydrocolloid systems (Fig. 2) revealed that after the 1 day storing the admixture of non-starchy hydrocolloids increased that parameter in respect to that for the paste of NPS1 free of the admixture. It could point to binding water in the relevant pastes in the initial stage of the formation of the networks. After 30 days the mean correlation times in the pastes rose above those found for the paste free of hydrocolloids. It could mean that every hydrocolloid inhibited removal of the water molecules from the polymeric structures limiting their mobility. Such phenomenon could result from the formation of more compact structures within the pastes which resembled solid state structures.
Fig. 2 Changes of the mean correlation time in $5 \%(\mathrm{~m} / \mathrm{m})$ NPS1 pastes without and with the admixture of non-starchy hydrocolloids after $2 \mathrm{~h}$ ( 0.12 day) and after 1,30 and 90 days storing at $5^{\circ} \mathrm{C}$

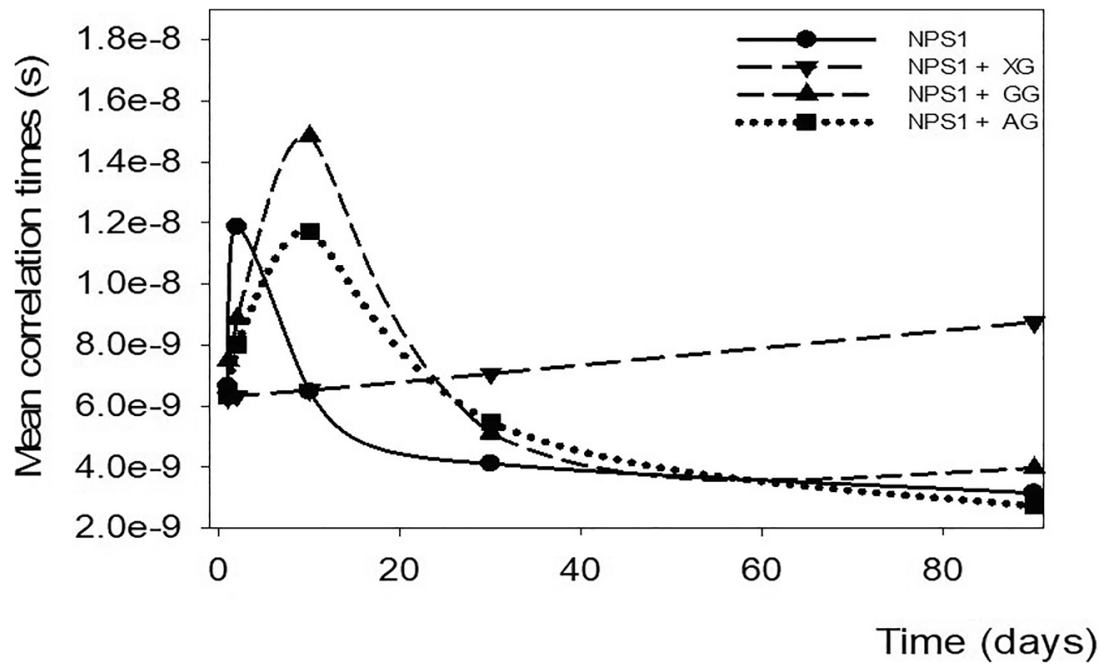


Fig. 3 Changes of the mean correlation time in $5 \%(\mathrm{~m} / \mathrm{m})$ NPS2 pastes without and with the admixture of non-starchy hydrocolloids after $2 \mathrm{~h}$ (0.12 day) and after 1,30 and 90 days storing at $5^{\circ} \mathrm{C}$

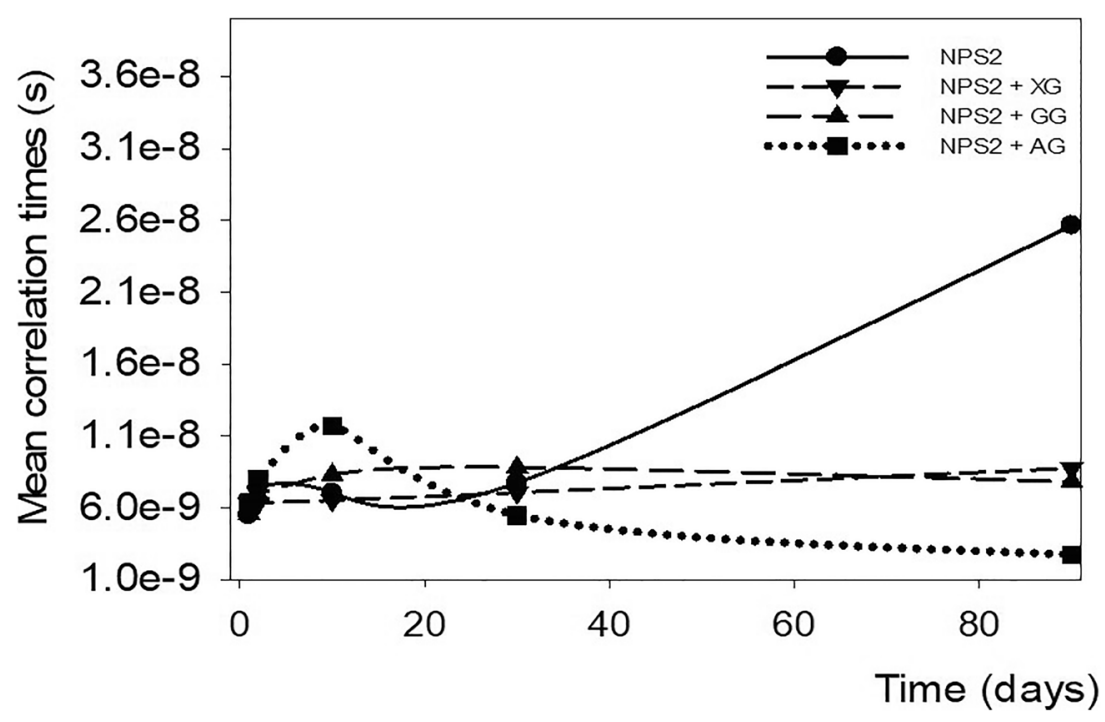

Blending WPS with hydrocolloids influenced the mean correlation time of the corresponding pastes to a various extent (Fig. 4). In the WPS binary pastes with GG the mean correlation time rose fast with the storage time pointing to a successive building structures of the solid state character. Pastes of WPS with XG behaved similarly, however, after the 90 day storage their mean correlation time decreased providing an evidence for a weakening the structure caused by progressing retrogradation. Moreover, one could suppose that after 30 days, in the pastes with GG and after 90 days in the pastes with XG and GG their structure was stronger than that of the WPS paste free of hydrocolloids. The mean relaxation time for the paste of WPS with AG was always lower than that for the paste free of hydrocolloid suggesting that it was more fluidal and disposed with lower viscosity.
Fig. 4 Changes of the mean correlation time in $5 \%(\mathrm{~m} / \mathrm{m})$ WPS pastes without and with the admixture of non-starchy hydrocolloids after $2 \mathrm{~h}$ ( 0.12 day) and after 1,30 and 90 days storing at $5^{\circ} \mathrm{C}$

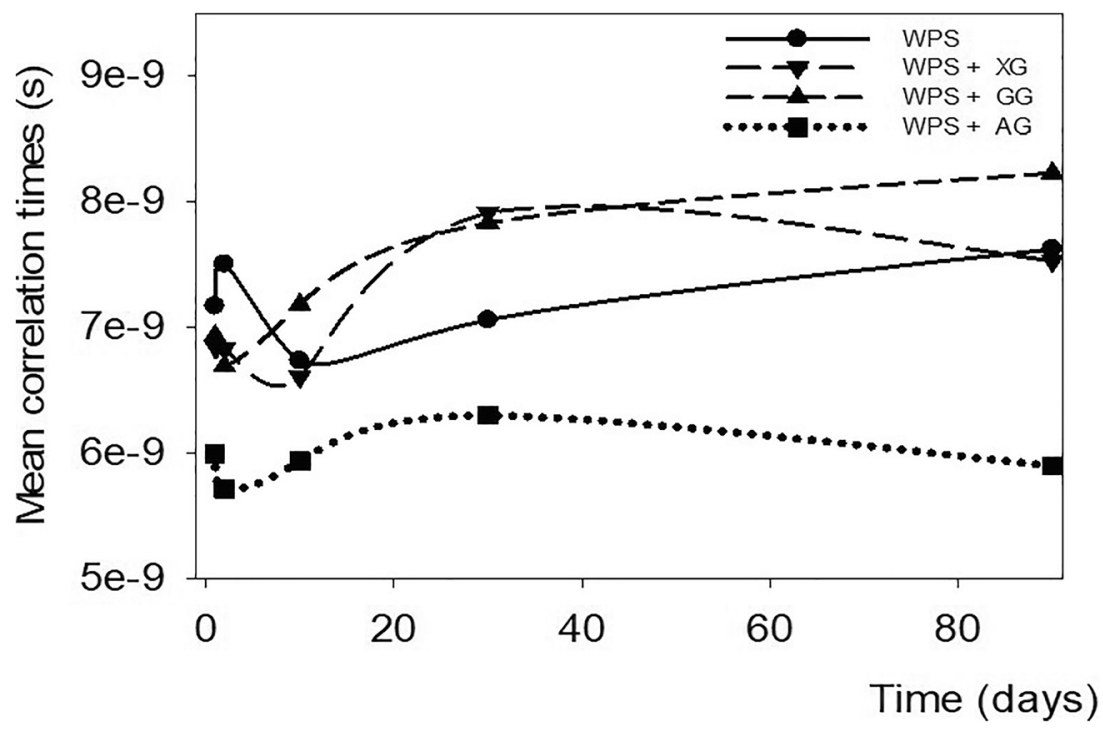




\section{Conclusion}

Susceptibility of pastes of potato starch to retrogradation was controlled, first of all, by the content of amylose. Amylose favored retrogradation. On the initial period of storing the length of the amylose chains played an essential role promoting retrogradation. Apart from NPS1 containing most amylose also WPS containing amylose of lower molecular weight readily retrograded.

Non-starchy polysaccharide hydrocolloids applied for blending potato starches influenced molecular properties of water in the pastes, particularly on long-term retrogradation. Admixture of Arabic gum to both normal potato starches inhibited rotation of the water molecules within first 10 days of storing, however, on the prolonged storage the water molecules within those systems reached the highest mobility. Admixture of that hydrocolloid to waxy potato starch resulted in an essential reduction of the mean correlation time what was associated with an intensification of the mobility of the water molecules due to considerable interactions of that hydrocolloid with short amylopectin chains. In the blends of waxy starch with guar and xanthan gums inhibition of rotational movements of the water molecules was observed after 10 days of storage. Since in hydrocolloid free pastes of waxy starch mobility of water did not change in time the result might suggest that both hydrocolloids bound water. In case of both normal potato starches xanthan gum determined long-term changes of the mobility of the water molecules and that effect was observed in the system of the highest, 30\%, content of amylose. In such system after the 30 days storing arresting water molecules in the paste structure played a principal role in limiting their rotation. That effect was not observed in the pastes of lower amylose content because the way of binding water in starch significantly limited rotation of the water molecules.

Acknowledgements This project was financed from the funds of the National Science Centre of Poland awarded basing on the decision number UMO-2013/11/B/NZ9/01951.

\section{Compliance with Ethical Standards}

Conflict of Interest The authors declare that they have no conflict of interest.

Open Access This article is distributed under the terms of the Creative Commons Attribution 4.0 International License (http:// creativecommons.org/licenses/by/4.0/), which permits unrestricted use, distribution, and reproduction in any medium, provided you give appropriate credit to the original author(s) and the source, provide a link to the Creative Commons license, and indicate if changes were made.

\section{References}

1. W.A. Atwell, L.F. Hood, D.R. Lineback, E. Varriano-Marston, H.F. Zobel, Cereal Foods World 33, 306 (1988)

2. M. Gudmundsson, Thermochim. Acta 246(2), 329-341 (1994)

3. J.-O. Kim, W.-S. Kim, M.-S. Shin, Starch/Staerke 49(2), 71-75 (1997)

4. I.A. Farhat, J.M.V. Blanshard, J.R. Mitchell, Biopolymers 53(5), 411-422 (2000)

5. S. Yu, Y. Zhang, Y. Ge, Y. Zhang, T. Sun, Y. Jiao, X.-Q. Zheng, J. Food Process Eng. 36, 793 (2013)

6. Y.Y. Xie, X.P. Hu, Z.Y. Jin, X.M. Xu, H.Q. Chen, Int. J. Biol. Macromol. 67, 79-84 (2014)

7. M.T. Kalichevsky, P.D. Orford, S.G. Ring, Carbohydr. Res. 198(1), 49-55 (1990)

8. P. Roulet, W.M. Maclnnes, D. Gumy, P. Mursch, Starch/Staerke 42(3), 99-101 (1990)

9. J. Silverio, H. Fredriksson, R. Andersson, A.-C. Eliasson, P. Aman, Carbohydr. Polym. 42(2), 175-184 (2000)

10. K. Kohyama, J. Matsuki, T. Yasui, T. Sasaki, Carbohydr. Polym. 58(1), 71-77 (2004)

11. Y.-.H. Chang, J.-.H. Lin, Food Hydrocolloid 21, 645 (2007)

12. H. Fredriksson, J. Silverio, R. Andersson, A.-C. Eliasson, P. Aman, Carbohydr. Polym. 35(3-4), 119-134 (1998)

13. H. Liu, L. Yu, F. Xie, L. Chen, Carbohydr. Polym. 65(3), 357363 (2006)

14. K. Jouppila, J. Kansikas, Y.H. Roos, Carbohydr. Polym. 36(2-3), 143-149 (1998)

15. M.H. Ong, J.M.V. Blanshard, J. Cereal Sci. 21(3), 251-260 (1995)

16. J.F. Aguirre, C.A. Osella, C.R. Carrara, H.D. Sanchez, M.P. Buera, Starch/Staerke 63(9), 587-593 (2011)

17. K.O. Adebowale, O.S. Lawal, J. Sci. Food Agr. 83, 1541 (2003)

18. M.G. Sajilata, R.S. Singhal, P.R. Kulkarni, Compr. Rev. Food Sci. F. 5(1), 1-17 (2006)

19. A. Sharma, B.S. Yadav, R.B. Ritika, Food Rev. Int. 24, 193 (2008)

20. M. Krystyjan, G. Adamczyk, M. Sikora, P. Tomasik, Food Hydrocoll. 31, 270 (2008)

21. S. Wang, C. Li, L. Coopeland, Q. Niu, S. Wang, Compr. Rev. Food Sci. F. 14(5), 568-585 (2015)

22. C. Perera, R. Hoover, Food Chem. 64(3), 361-375 (1999)

23. T. Funami, Y. Kataoka, T. Omoto, Y. Goto, I. Asai, K. Nishinari, Food Hydrocoll. 19(1), 1-13 (2005)

24. M. Sikora, S. Kowalski, P. Tomasik, Food Hydrocoll. 22(5), $943-$ 952 (2008)

25. S. Kowalski, M. Sikora, P. Tomasik, M. Krystyjan, Polimery 53(6), 34 (2008)

26. M. Sikora, P. Tomasik, M. Krystyjan, J. Krawontka, Polimery 55(07/08), 582-590 (2010)

27. M. Sikora, P. Tomasik, M. Krystyjan, Starch/Staerke 62(7), 341349 (2010)

28. S. Charoenrein, O. Tatirat, K. Rengsutthi, M. Thongngam, Carbohydr. Polym. 83(1), 291-296 (2011)

29. R.K. Song, M. Huang, B. Li, B. Zhou, Nutrients 4(6), 425-435 (2012)

30. L. Chen, Y. Tian, Q. Tong, Z. Zhang, Z. Jin, Food Chem. 214, 702 (2017)

31. C. Mutungi, L. Passauer, C. Onyango, D. Jaros, H. Rohm, Carbohydr. Polym. 87(1), 598-606 (2012)

32. K.S. Lewen, T. Paeschke, J. Reid, P. Molitor, S.J. Schmidt, J. Agric. Food Chem. 51(8), 2348-2358 (2003)

33. A. Abd Karim, N.H. Norziah, C.C. Seow, Food Chem. 71(1), 9-36 (2000)

34. H.M. Baranowska, M. Sikora, S. Kowalski, P. Tomasik, Food Hydrocoll. 22(2), 336-345 (2008)

35. H.M. Baranowska, M. Sikora, M. Krystyjan, P. Tomasik, Polimery 56(6), 478-483 (2011) 
36. E. Brosio R. Gianferri, in: Basic NMR in Foods Characterization, ed. by E. Brosio (Research Singpost, Kerala, 2009), pp. 9-37

37. P.S. Belton, in Advances in Magnetic Resonance in Food Science, ed. by P.S. Belton, B.P. Hills, G.A. Webb (Royal Society of Chemistry, Cambridge, 1999) pp. 115-125

38. W.B. Morrison, B. Laignelet, J. Cereal Sci. 1(1), 9-20 (1983)

39. W.P. Weglarz, H. Harańczyk, J. Phys. D. Appl. Phys. 33(15), 1909$1920(2000)$

40. J. Stangierski, R. Rezler, H.M. Baranowska, S. Poliszko, Czech J. Food Sci. 30(5), 404-411 (2012)

41. H.M. Baranowska, M. Sikora, M. Krystyjan, P. Tomasik, J. Food Eng. 109(4), 685-690 (2012)

42. A. Dobosz, M. Sikora, M. Krystyjan, P. Tomasik, R. Lach, B. Borczak, W. Berski, M. Lukasiewicz, J. Sci, Food Agr. 99(5), 2393-2403 (2018). https://doi.org/10.1002/jsfa.9446
43. M.R. Hansen, A. Blennow, I. Farhat, L. Nørgaard, S. Pedersen, S.B. Engelsen, Food Hydrocoll. 23(8), 2038-2048 (2009)

44. J.F. Fundo, A.L. Amaro, A.R. Madureira, A. Carvalho, G. Feio, C.L.M. Silva, M.A.C. Quintas, J. Food Eng. 167, 71-76 (2015)

45. P.S. Belton, Int. J. Biol. Macromol. 21(1-2), 81-88 (1997)

46. J. Stangierski, H.M. Baranowska, Food Bioprocess Technol. 8(12), 2359-2367 (2015)

47. N. Bloembergen, E.M. Purcell, R.V. Pound, Phys. Rev. 734, 679 (1948)

48. H. Tang, P.S. Belton in Advances in Magnetic Resonance in Food Science, ed. By P.S. Belton, B.P. Hills, G.A. Webb (Royal Society of Chemistry, Cambridge, 1999), 166-184

Publisher's Note Springer Nature remains neutral with regard to jurisdictional claims in published maps and institutional affiliations. 